\title{
NEUTRONIC CALCULATIONS \\ FOR EXPERIMENTS WITH LIGHT WATER \\ REACTOR FUEL IN PBF
}

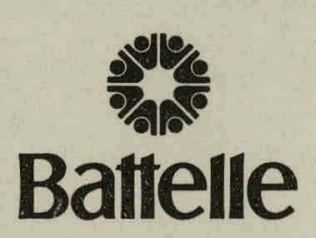

Pacific Northwest Laboratories

Richland, Washington 99352

This report is intended primarily for internal use by the sponsoring organization and Battelle.

Prepared for the U.S. Atomic Energy Commission under Contract AT(45-1):1830 


\section{DISCLAIMER}

This report was prepared as an account of work sponsored by an agency of the United States Government. Neither the United States Government nor any agency Thereof, nor any of their employees, makes any warranty, express or implied, or assumes any legal liability or responsibility for the accuracy, completeness, or usefulness of any information, apparatus, product, or process disclosed, or represents that its use would not infringe privately owned rights. Reference herein to any specific commercial product, process, or service by trade name, trademark, manufacturer, or otherwise does not necessarily constitute or imply its endorsement, recommendation, or favoring by the United States Government or any agency thereof. The views and opinions of authors expressed herein do not necessarily state or reflect those of the United States Government or any agency thereof. 


\section{DISCLAIMER}

Portions of this document may be illegible in electronic image products. Images are produced from the best available original document. 
NOTICE

The report was prepared as an account of work sponsored by the United States Government. Neither the United States nor the United States Atomic Energy Commission, nor any of their employees, nor any of their contractors, subcontractors, or their employees, makes any warranty, express or implied, or assumes any legal liability or responsibility for the accuracy, completeness or usefulness of any information, apparatus, product or process disclosed, or represents that its use would not infringe privately owned rights.

\section{PACIFIC NORTHWEST LABORATORY operated by \\ BATTELLE \\ for the \\ U.S. ATOMIC ENERGY COMMISSION \\ Under Contract AT(45-1)-1830}

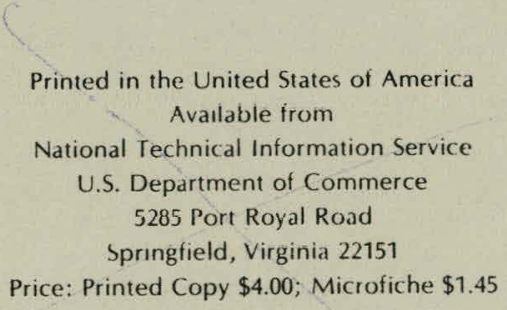




\section{NEUTRONIC CALCULATIONS FOR EXPERIMENTS WITH}

LIGHT WATER REACTOR FUEL IN PBF

by

U. P. Jenquin

D. H. Thomsen

C. M. Heeb

\section{August 1974}

\section{BATTELLE \\ PACIFIC NORTHWEST LABORATORIES RICHLAND, WASHINGTON}


BOWL- B-371

CONTENTS

LIST OF FIGURES.

LIST OF TABLES •

INTRODUCTION. • • • • • • • • • • • • • • • • • • • • •

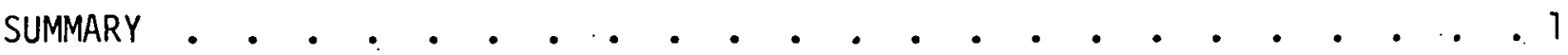

TECHNICAL APPROACH. • • • • • • • • • • • • • . . • • . . 2

Monte Carlo • • • • • • • • • • • • • • • • • . 2

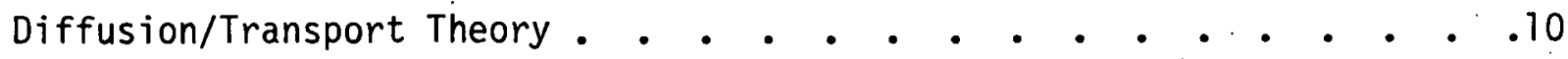

RESULTS • • • • • • • • • • • • • • • • • • • • • • 12

Verification. • • • • • • • • • • • • • • • • . 12

4-Rod Bundles • • • • • • • • • • • • • • • • • •

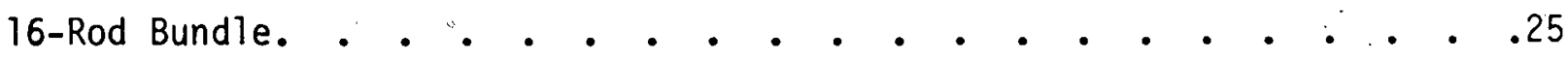

Accuracy • • • • • • • • • • • • • • • • • • . . . . . • • •

REFERENCES • • • • • • • • • • • • • • • • • • • • •

DISTRIBUTION 


\section{LIST OF FIGURES}

1 Geometry Used in the Monte Carlo Calculation for a 4-Rod Bundle in PBF. . . . . . . . . . . . . . . . . . . 4

2 Geometry Used in the Monte Carlo. Calculation for a 16-Rod Bundle in PBF. . . . . . . . . . . . . . . . 5

3 Fuel Region Boundaries for Monte Carlo Calculations of 4-Rod Bundles. • . . . . . . . . . . . . . . 6

4 Fuel Region Boundaries for Monte Carlo Calculations of

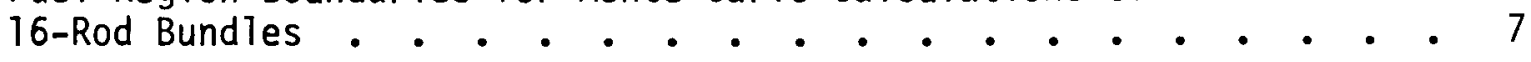

5 Peak Linear Power as a Function of Enrichment for 4-Rod Bundles. • • • • • • • • • • • • • • • • • • 15

6 Power Distribution in a $10 \%$ Enriched $\mathrm{UO}_{2}$ BWR Rod . • : : • • . 17

7 Power Distribution in a $10 \%$ Enriched $\mathrm{UO}_{2}$ Large PWR Rod . • . • 18

8 Power Distribution in a $10 \%$ Enriched $\mathrm{UO}_{2}$ Smal1 PWR Rod . . . . . 19

9 Power Distribution in an $8 \%$ Enriched $\mathrm{UO}_{2}-\mathrm{PuO}_{2} \mathrm{BWR}$ Rod . • • • 20

10 Power Distribution in an $8 \%$ Enriched $\mathrm{UO}_{2}-\mathrm{PuO}_{2}$ Large PWR Rod . . 21

11 Effect of U-235 Enrichment on Thermal Power Distribution for BWR Test Pins in PBF . . . . . . . . . . . . . . 22

12 Effect of Plutonium Enrichment on Thermal Power Distribution for BWR Test Pins in PBF . . . . . . . . . . . . . . . 23

13. Effect of Pellet Size on Thermal Power Distribution for $10 \%$ Enriched $\mathrm{UO}_{2}$ Test Pins in PBF. . - . . - . . . . . . . . 24

14 Enrichment Distributions for Large PWR 16-Rod Bundle Calculations • • • • • • • • • • • • • • . 26

15 Power Distribution in the Corner Rod of a 16-Rod Bundle . • • . 28 16 Power Distribution in the Edge Rod of a 16-Rod Bundle . • • • 29 17 Power Distribution in the Center Rod of a 16-Rod, Bundle. . . . 30 


\section{LIST OF TABLES}

I Boundary Current Sources Used in the Monte Carlo Calculations . . . 9

II Description of Test Fuel Region . . . . . . . . . . . . . 11

III Boundaries for 4-Group Structure . . . . . . . . . . . . 11

IV Description of Test Pins . . . . . . . . . . . . . . . 12

V Peak Rod Power Per Foot in 4-Rod Bundles . . . . . . . . . . 14

VI 16-Rod Bundle Power Calculations at Various Enrichments . . . . . 27 


\section{NEUTRONIC CALCULATIONS FOR EXPERIMENTS WITH}

LIGHT WATER REACTOR FUEL IN PBF

U. P. Jenquin, D. H. Thomsen and C. M. Heeb

INTRODUCTION

Experiments are to be performed in the PBF with fuel rods representative of light water reactor fuel. Neutronic calculations have been performed to specify the rod enrichment required to give desired powers. In one set of experiments there will be four identical test rods placed symmetrically in the center of PBF. In addition, a 16-rod experiment will be performed with varying enrichments in the rods in order to flatten the power distribution.

The 4-rod experiments will utilize fuel representative of BWR, large PWR, and small PWR pins. BWR and large PWR 4-rod experiments will also be performed utilizing plutonium in the fuel. The 16-rod experiment will utilize large PWR pins enriched with U-235. It is desired that these rods produce a maximum power of 21 to $25 \mathrm{~kW} / \mathrm{ft}$.

SUMMARY

Linear power densities as a function of enrichment were determined for test pins enriched with either uranium-235 or plutonium. In addition, a calculation was made for a MAPI rod ${ }^{(1)}$ as a check of our methods versus ANC methods. Results of calculations for the test rods of interest are plotted on Figure 5. The results are presented as peak axial power versus enrichment assuming a PBF core power of $30 \mathrm{MW}$. To obtain $25 \mathrm{~kW} / \mathrm{ft}$ in the 4-rod experiments, the BWR pins must be enriched to $8 \% 235 \mathrm{U}$, the large PWR pins must be enriched 
to $12 \% 235 \mathrm{U}$, and the small PWR pins must be enriched to $16 \% 235 \mathrm{U}$. For mixed oxide fuel, the BWR pins must be enriched to $6 \% \mathrm{Pu}$ and the large PWR pins must be enriched to $9 \% \mathrm{Pu}$ for the plutonium isotopic composition assumed. The radial and azimuthal power distributions within the test pins were also determined.

The 16-rod bundle of large PWR pins is not capable of producing $25 \mathrm{~kW} / \mathrm{ft}$. With an average enrichment of $60 \%$, the power (peak axial, average radial) is $16.6 \mathrm{~kW} / \mathrm{ft}$.

\section{TECHNICAL APPROACH}

The overall approach to the problem was similar to what ANC has done in the past. (1) Few-group diffusion theory calculations were performed for the PBF core with the experiment in the center of it. The enrichment of the test pins was varied to determine the power as a function of enrichment. Monte carlo calculations were performed for the test region using currents for the neutron source.

\section{Monte Carlo}

A calculation of the experiment and the PBF core with a monte carlo code is too time consuming to be feasible. Therefore, the experiment was isolated and a set of currents used as a source at the inside edge of the in-pile tube (IPT). The currents were calculated with the transport code DTF-IV ${ }^{(2)}$ using 17 energy groups and cylindrical geometry. These currents were then used as a source for the BMC monte carlo code ${ }^{(3)}$. The monte carlo calculation followed these source neutrons until they were absorbed or leaked. The fission neutrons which were produced were also followed. 
The geometry used for the monte carlo calculation included a two-dimensional representation of the regions inside the IPT as shown in Figures 1 and 2 . Figure 1 shows the geometry for the 4-rod cases and Figure 2 shows the geometry for the 16-rod cases. For the 4-rod bundle, the fuel rod was divided into equal volume regions as shown in Figure 3. Because of diagonal symmetry, fluxes for symmetric regions on each side of the diagonal were averaged together. The clad was smeared in with the gap and the clad density was reduced proportionately.

For the 16-rod bundles, the pins were divided as in Figure 4. Only two radial regions in each octant were used. The corner and center pins have diagonal symmetry, but the edge pins required flux calculations for all octants.

The BMC monte carlo code is a three-dimensional continuous slowing down neutron monte carlo code. The energy range from fission through thermal is included. The reaction types are elastic scattering, inelastic scattering, $n-2 n$ scattering, fission, and capture. $n-2 n$ production and absorption are accounted for by weight modification. The thermal scattering for oxygen is calculated using the ideal gas model while the hydrogen scattering below $1.855 \mathrm{eV}$ is calculated using a kernel based on the ENDF/B scattering model for hydrogen in water.

The cross sections for all isotopes except zirconium were calculated from ENDF/B version 3 data. Zirconium cross sections were obtained from ENDF/B version 4 data. The cross sections are averaged over 190 energy groups. The 20 most important $238 \mathrm{U}$ resonances and the $1.0 \mathrm{eV} 240 \mathrm{Pu}$ resonance are calculated by the code for each energy point using the Doppler-broadened Breit Wigner singlelevel formulae. The other resonances and the unresolved resonances are averaged using the Doppler broadened cross sections and a flux approximated by $\phi(E)=\frac{1}{\sigma_{T}(E)+\sigma_{m}}$ where $\sigma_{m}$ is the effective off resonance scattering cross section 
FIGURE 1. Geometry Used in the Monte Carlo Calculation for a 4-Rod Bundle in PBF

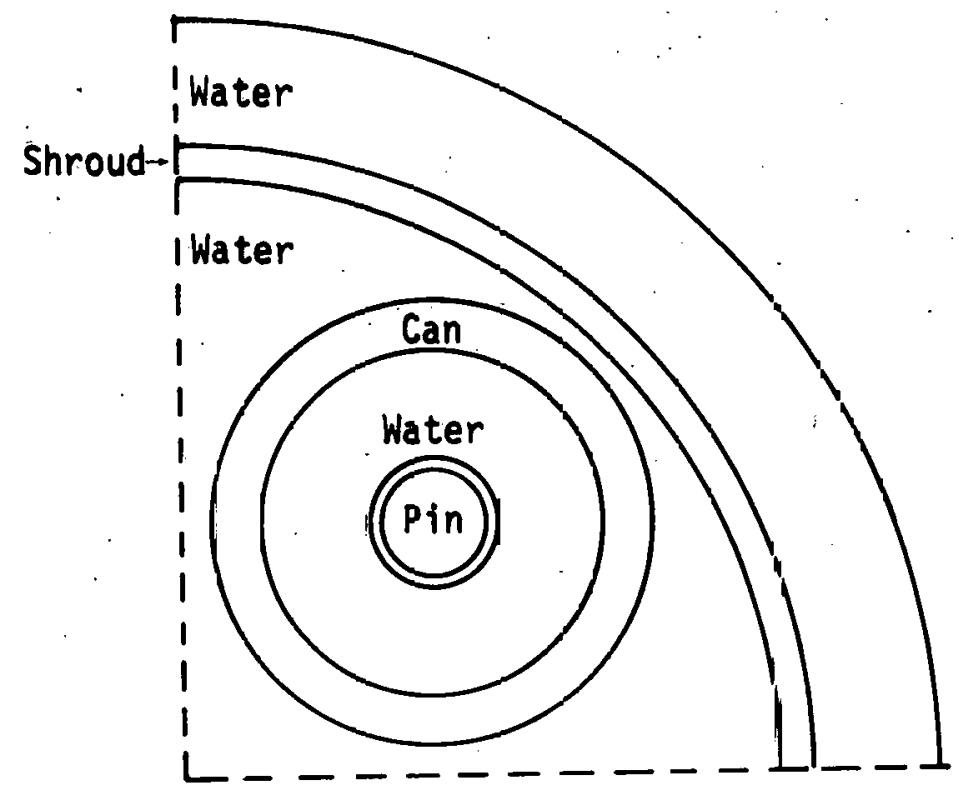

\begin{tabular}{ll}
\multicolumn{2}{c}{ Dimensions, in. } \\
Pitch & $115 / 16$ \\
Pellet OD* & .416 \\
Clad OD* & $i 93$ \\
Can ID & $i 3 / 8$ \\
Can OD & $3 / 4$ \\
Shroud ID & $43 / 4$ \\
Shroud OD & 5 \\
IPT ID & 6
\end{tabular}

*Dependent on type of test pin 
FIGURE 2. Geometry Used in the Monte Carlo Calculation for a 16-Rod Bundle in PBF

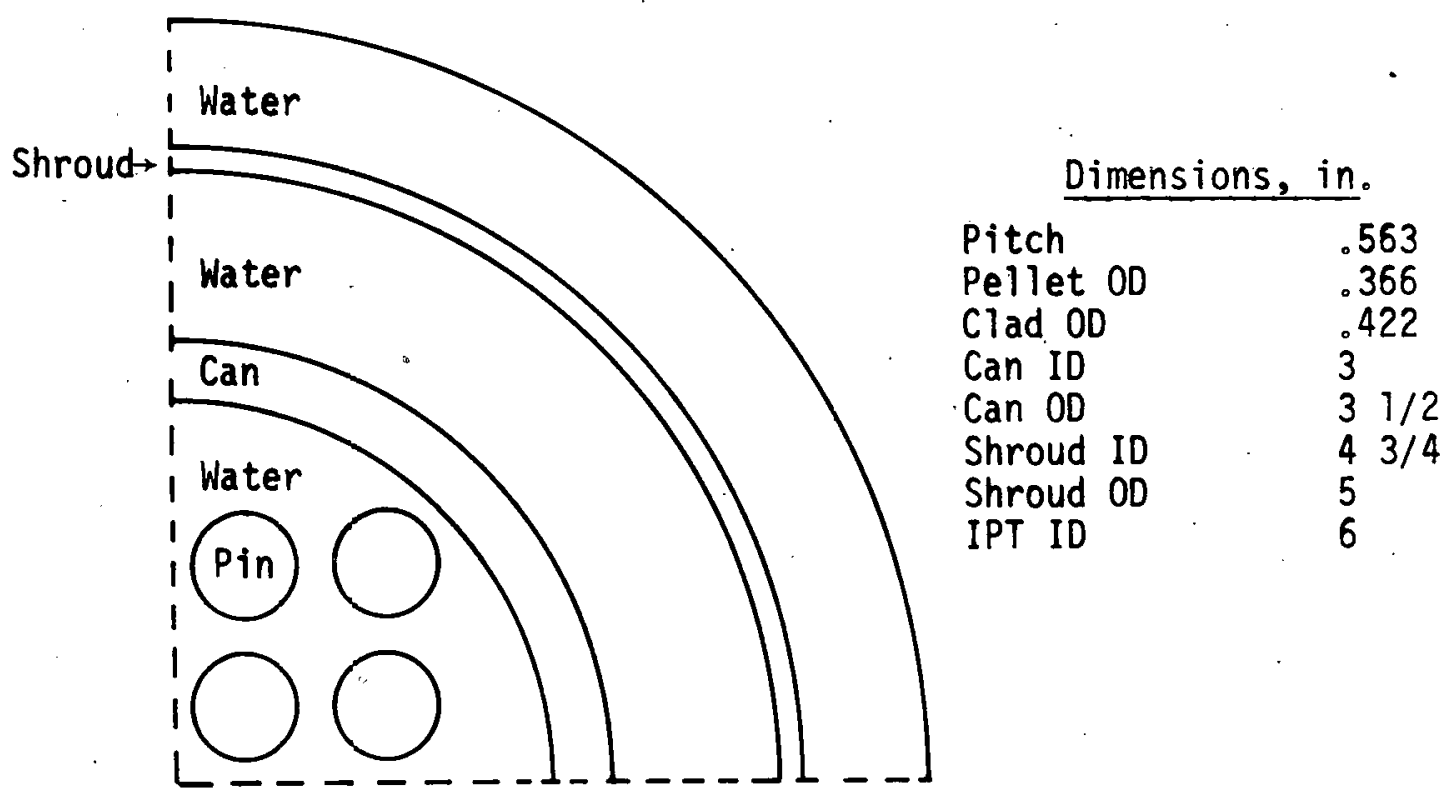


FIGURE 3. Fuel Region Boundaries for Monte Carlo

Calculations of 4-Rod Bundles

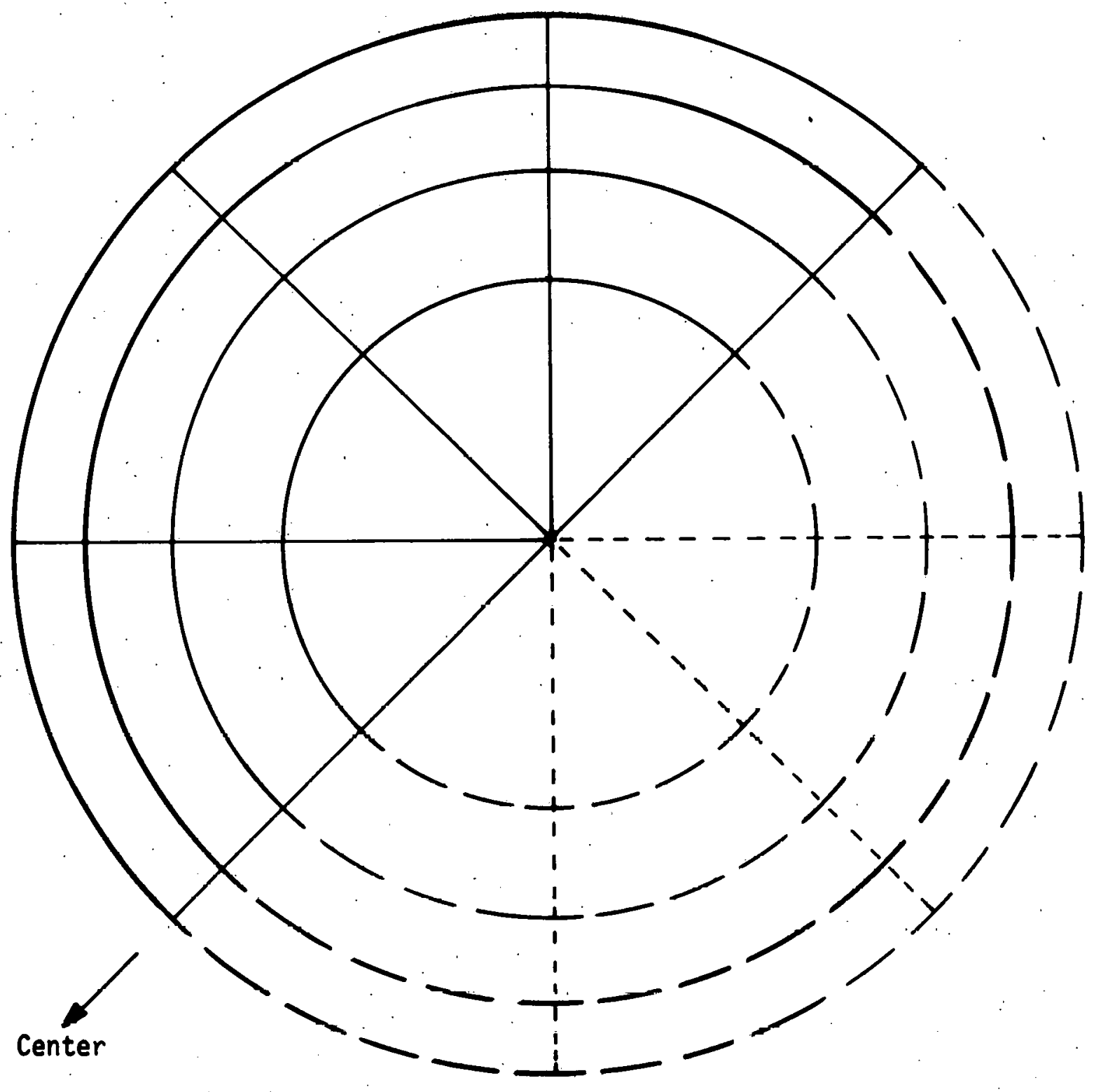




\section{FIGURE 4. Fuel Region Boundaries for Monte Cario}

Calculations of 16-Rod Bundles

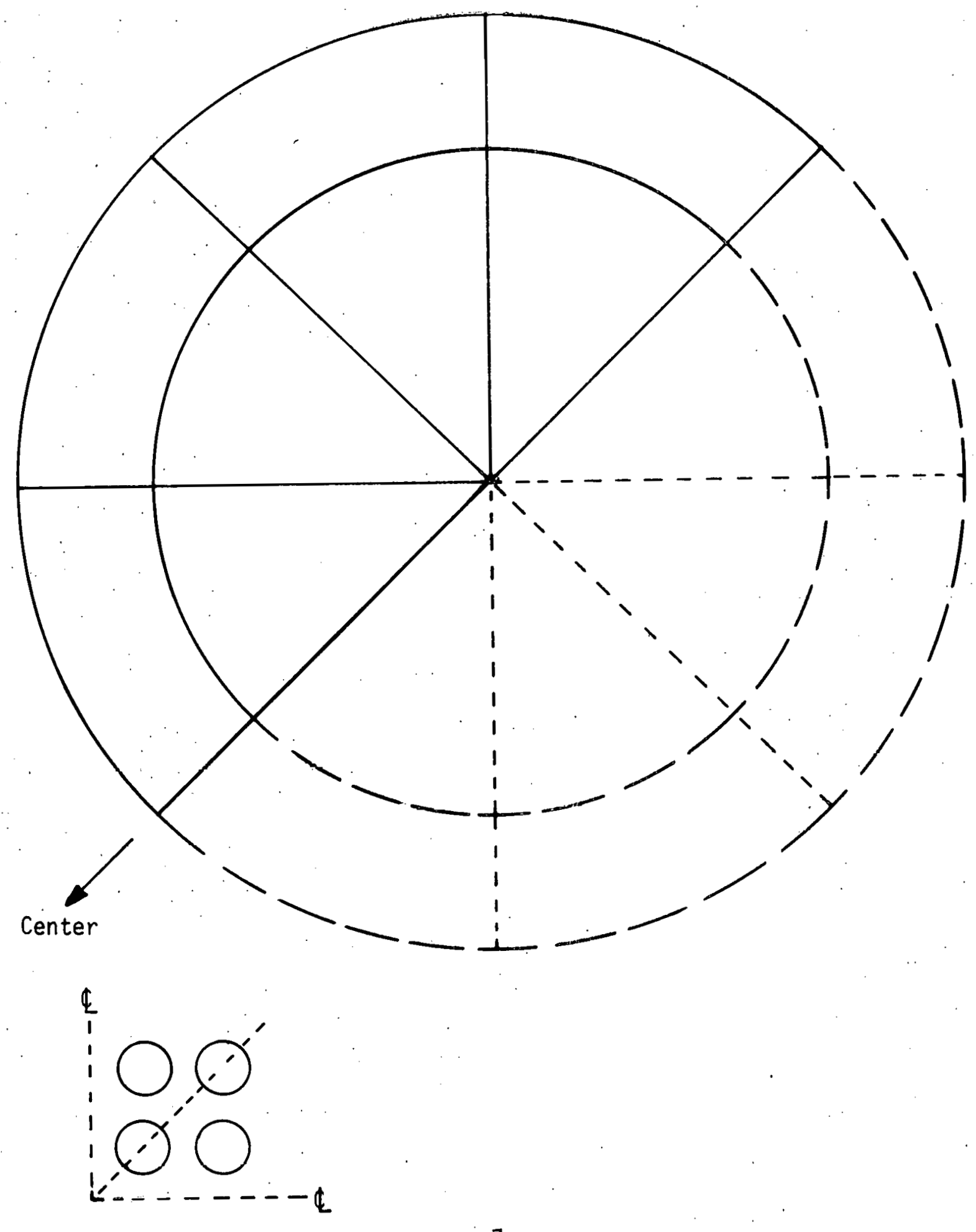


due to other scatterers in the material and to the rod size, lattice spacing, and moderator density.

The source for BMC was the 17-group inward partial currents calculated by DTF-IV. The current was assumed to be isotropic. The energy distribution of the current in each of the 16 epithermal groups was assumed to be proportional to $1 / E$ while the thermal current energy distribution was obtained using the 30-group fluxes from a thermalization calculation. It was necessary to adjust the $1 / E$ slowing down portion of the thermal spectrum to better match the $1 / E$ epithermal spectrum while conserving the total thermal current. This was done by increasing the $1 / E$ slowing down tail while lowering the Maxwellian in the thermal range such that the total integral was conserved. The exact $1 / E$ normalization is not known, but based upon experience a value of 0.95 times the 1/E value in group 16 was used. Table I gives the 17-group currents used in the calculations. Different currents were calculated for the 4-rod bundles of $\mathrm{UO}_{2}$ rods, the 4-rod bundles of mixed oxide rods, and the 16-rod bundle of large PWR $\mathrm{UO}_{2}$ rods. Importance weighting was used in selecting the neutron energies and also different minimum and survival weight staridards were used in the various regions to reduce the calculational time. The weighting which was selected appears to have significantiy increased the accuracy of the power density in each region relative to other regions. This accuracy is obtained at the expense of accuracy in the total power.

Fluxes and leakages are tallied using a beam estimator. The statistics on the answers are obtained using a number of batches and averaging the results. The quoted error bars are one standard deviation from the mean. The uncertainties are due only to statistical variations and not to other sources such as cross section uncertainties. The monte carlo results are used to normalize the diffusion/transport theory results. 
TABLE I. Boundary Current Sources Used in the Monte Carlo Calculations

\begin{tabular}{|c|c|c|c|c|}
\hline \multirow[b]{2}{*}{ Group No. } & \multirow[b]{2}{*}{ Lower Energy, eV } & \multicolumn{3}{|c|}{ Current ${ }^{*}$, neutrons $/ \mathrm{cm}^{2} \times 10^{12}$} \\
\hline & & $10 \% \mathrm{UO}_{2}$ Pins & $\begin{array}{c}8 \% \text { Mixed } \\
\text { 0xide Pins } \\
\end{array}$ & $\begin{array}{c}16-\text { Rod } \mathrm{VO}_{2} \\
\text { Bundle } \\
\end{array}$ \\
\hline 1 & $4.724 \times 10^{6}$ & 0.353 & 0.353 & 0.351 \\
\hline 2 & $2.231 \times 10^{6}$ & 2.07 & 2.09 & 2.06 \\
\hline 3 & $8.208 \times 10^{5}$ & 5.60 & 5.68 & 5.48 \\
\hline 4 & $3.020 \times 10^{5}$ & 5.20 & 5.26 & 4.94 \\
\hline 5 & $1.111 \times 10^{5}$ & 3.61 & 3.66 & 3.36 \\
\hline 6 & $4.087 \times 10^{4}$ & 2.30 & 2.32 & $2: 10$ \\
\hline 7 & $1.171 \times 10^{4}$ & 1.59 & 1.61 & 1.43 \\
\hline 8 & 2612.5 & 2.37 & 2.41 & 2.17 \\
\hline 9 & 582.9 & 2.24 & 2.26 & 2.07 \\
\hline 10 & 167.0 & 1.76 & 1.78 & 1.63 \\
\hline 11. & 47.85 & 1.68 & 1.81 & 1.57 \\
\hline 12 & 17.60 & 1.27 & 1.28 & 1.19 \\
\hline 13 & 6.476 & 1.18 & 1.19 & 1.12 \\
\hline 14 & 2.382 & 1.06 & 1.08 & 1.02 \\
\hline 15 & 1.125 & 0.770 & 0.781 & 0.748 \\
\hline 16 & 0.683 & 0.487 & 0.495 & 0.478 \\
\hline 17 & 0.0 & 3.34 & 3.62 & 4.18 \\
\hline Total & & 36.88 & 37.68 & 35.90 \\
\hline
\end{tabular}

*Bascd on 30 MW PBF reactor power and a 1.5 axial peaking factor. 


\section{Diffusion/Transport Theory}

Two-dimensional diffusion theory $(2 \mathrm{DB}(4))$ calculations of the PBF core with the test fuel in the center were performed to determine the power generation in the test fuel as a function of enrichment. The core specifications used were those shown in Figure 1 of Reference 5. Isotopic compositions for various regions were taken from Tables A-I and A-II of Reference 5. Each driver fuel was represented by 4 mesh points $(2 \times 2)$ or about 1 mesh point per square centimeter. The test pin, zirconium can, zirconium shroud, and enclosed water were homogenized into one region. The $2 D B$ calculations used an axial buckling of $8.71 \times 10^{-4} \mathrm{~cm}^{-2}$.

Four-group cross sections for the driver fuel, moderator, and aluminum cans were obtained from HRG3 ${ }^{(6)}$ (slowing down) and BRT-I ${ }^{(7)}$ (thermal) transport theory calculations. The fuel temperature was assumed to be $1545^{\circ} \mathrm{F}$. The water was assumed to be at $96^{\circ} \mathrm{F}$. Four-group cross sections for the moderator, al uminum, inconel, stainless steel reflector pin, aluminum reflector pin, transient rod follower, and control rod follower regions were obtained by editing over the driver fuel spectrum with appropriate densities from Tables A-I and A-II of Reference 5.

Four-group cross sections for the test region were obtained from HRG3 and BRT-I using the description shown in Table II. The fuel temperature was assumed to be $2600^{\circ} \mathrm{F}$. The water was assumed to be at $650^{\circ} \mathrm{F}$ and 2200 psia $(\mathrm{N}=.02207$ molecules $/ \mathrm{b}-\mathrm{cm})$. The boundaries for the four energy groups are listed in Table III. 
TABLE II. Description of Test Fuel Region

\begin{tabular}{|c|c|c|}
\hline Reg. & Material & O.D., in \\
\hline 1 & Fuel & * \\
\hline 2 & Clad & $\star$ \\
\hline 3 & Moderator & 1.375 \\
\hline 4 & Can & 1.750 \\
\hline 5 & Moderator & 2.375 \\
\hline 6 & Shroud & 2.500 \\
\hline
\end{tabular}

*Dependent on type of test pin; see Table IV.

TABLE III。 Boundaries for 4-Group Structure

$\begin{array}{cc}\text { Group No. } & \text { Lower Energy, eV } \\ 1 & 1.17 \times 10^{4} \\ 2 & 2.38 \\ 3 & 0.683 \\ 4 & 0.0\end{array}$

A description of the three types of test pins is summarized in Table IV. Untess specified otherwise, all calculations were performed with the fuel at 95\% T.D. or $10.41 \mathrm{~g} / \mathrm{cm}^{3}$. In the BRT-I and BMC calculations the clad and gap were homogenized into one region. The isotopic concentrations for the mixed oxide. rods were chosen so the plutonium would be representative of recycle Pu. The isotopic percentages are $70 / 20 / 7 / 3$ for $\mathrm{Pu}-239 / 240 / 241 / 242$ respectively. The uranium is taken as natural. The plutonium enrichment refers to percent of heavy atoms which are Pu. 
TABLE IV. Description of Test Pins

\begin{tabular}{|c|c|c|c|c|}
\hline Type & $\begin{array}{l}\text { Pellet } \\
0.0 ., \text { in. }\end{array}$ & $\begin{array}{c}\text { Gap } \\
\text { Thickness, in. }\end{array}$ & $\begin{array}{c}\text { Clad } \\
\text { Thickness, in. }\end{array}$ & $\begin{array}{c}\text { Clad } \\
\text { O.D., in. }\end{array}$ \\
\hline BWR & 0.416 & 0.0045 & 0.034 & 0.493 \\
\hline Large PWR & 0.366 & 0.004 & 0.024 & 0.422 \\
\hline Smal1 PWR & 0.324 & .0 .004 & 0.025 & 0.382 \\
\hline
\end{tabular}

The currents used in the monte carlo calculations were obtained from 17-group, one-dimensional transport theory calculations with DTF-IV. (2) The energy boundaries are listed in Table I. The radial model shown in Figure 7 of Reference 5 was used to describe the regions. Since there are no stainless steel shim pins in this model, the axial buckling was adjusted to give $k_{\text {eff }}$ of 1.00. The cross sections were obtained in the same manner as the 4-group cross sections.

\section{$\underline{\text { RESULTS }}$}

Calculations for 4-rod and 16-rod bundles were performed with monte carlo, transport theory, and diffusion theory methods. In addition, a test pin calculated previously by ANC $^{(1)}$ was also calculated in order to eliminate any obvious errors.

\section{Verification}

The MAPI rod with a zirconium can was run with BMC for a sufficient length of time to conclude that BMC was calculating approximately the same test pin power as RAFFLE ${ }^{(8)}$. A $2 D B$ calculation on the same rod resulted in a linear power value $4 \%$ lower than the RÁFFLE value ${ }^{(1)}$. Thus, both the monte carlo and diffusion theory calculations were consistent with ANC methods. 
One-dimensional 17-group transport theory calculations of the PBF core result in $k_{\text {eff }}$ values of 1.088 whereas two-dimensional 4-group diffusion theory gives $k_{\text {eff }}$ values of 1.000 . The major reason for this difference is the omission of the stainless steel shim pins in the first case.

Two-dimensional 2DB calculations indicate that the stainless steel shim pins in the PBF core are worth $-5.8 \% \Delta k / k$ when they are replaced by fuel pins. This value is slightly larger than the ANC estimate ${ }^{(9)}$ of $i-4 \% \Delta k / k$. A one-dimensional radial diffusion theory calculation gives a reactivity which is $0.5 \% \Delta \mathrm{k} / \mathrm{k}$ higher than the 2-D calculation. Thus, geometry does not have a very large effect on reactivity. The difference between transport and diffusion theory (1-D) is $2.5 \%$ $\Delta k / k$.

The transport theory calculations with varying amounts of axial leakage show that the current incident on the test region is sensitive to the buckling value. Therefore, the currents were obtained using an effective core height of 71 inches which results in a $k_{\text {eff }}$ value of 1.00 .

\section{4-Rod Bundles}

The monte carlo calculated values of linear peak rod power in the 4-rod bundles are listed in Table $V$. The results assume $30 \mathrm{MW}$ in PBF and an axial peaking factor of 1.5. The values for the mixed oxide rods assume the energy release per fission is $3 \%$ higher than for the $\mathrm{UO}_{2}$ rods. Linear peak rod powers calculated with diffusion theory are also shown in Table $V$. The diffusion theory values are slightly higher than the monte carlo values. These differences were utilized to adjust diffusion theory values for other enrichments. The resulting linear peak rod powers as a function of enrichment are shown in Figure 5. To obtain $25 \mathrm{~kW} / \mathrm{ft}$ the $\mathrm{UO}_{2}$ BWR pins must be enriched to $8 \% 235 \mathrm{U}$; the 1 arge $\mathrm{UO}_{2}$ 
TABLE V. Peak Rod Power in 4-Rod Bundles

\begin{tabular}{|c|c|c|}
\hline & \multicolumn{2}{|c|}{ Linear Power, $\mathrm{kW} / \mathrm{ft}$} \\
\hline Rod Description & $\begin{array}{l}\text { Diffusion } \\
\text { Theory }\end{array}$ & Monte Carlo \\
\hline $10 \%$ Enriched $\mathrm{UO}_{2}$ BWR Rods & 29.62 & $27.38 \pm 0.23$ \\
\hline $10 \%$ Enriched $\mathrm{UO}_{2}$ Large PWR Rods & & $23.18 \pm 0.19$ \\
\hline $10 \%$ Enriched $\mathrm{UO}_{2}$ Small PWR Rods & 21.56 & $20.12 \pm 0.17$ \\
\hline $\begin{array}{c}\text { 8\% Enriched Mixed 0xide } \\
\text { BWR Rods }\end{array}$ & 28.82 & $27.65 \pm 0.24$ \\
\hline $\begin{array}{l}\text { 8\% Enriched Mixed Oxide } \\
\text { large PWR Rods }\end{array}$ & 25.29 & $24.22 \pm 0.28$ \\
\hline
\end{tabular}


FIGURE 5. Peak !inear Power as a Function of Enrichment for 4-Rod Bundles

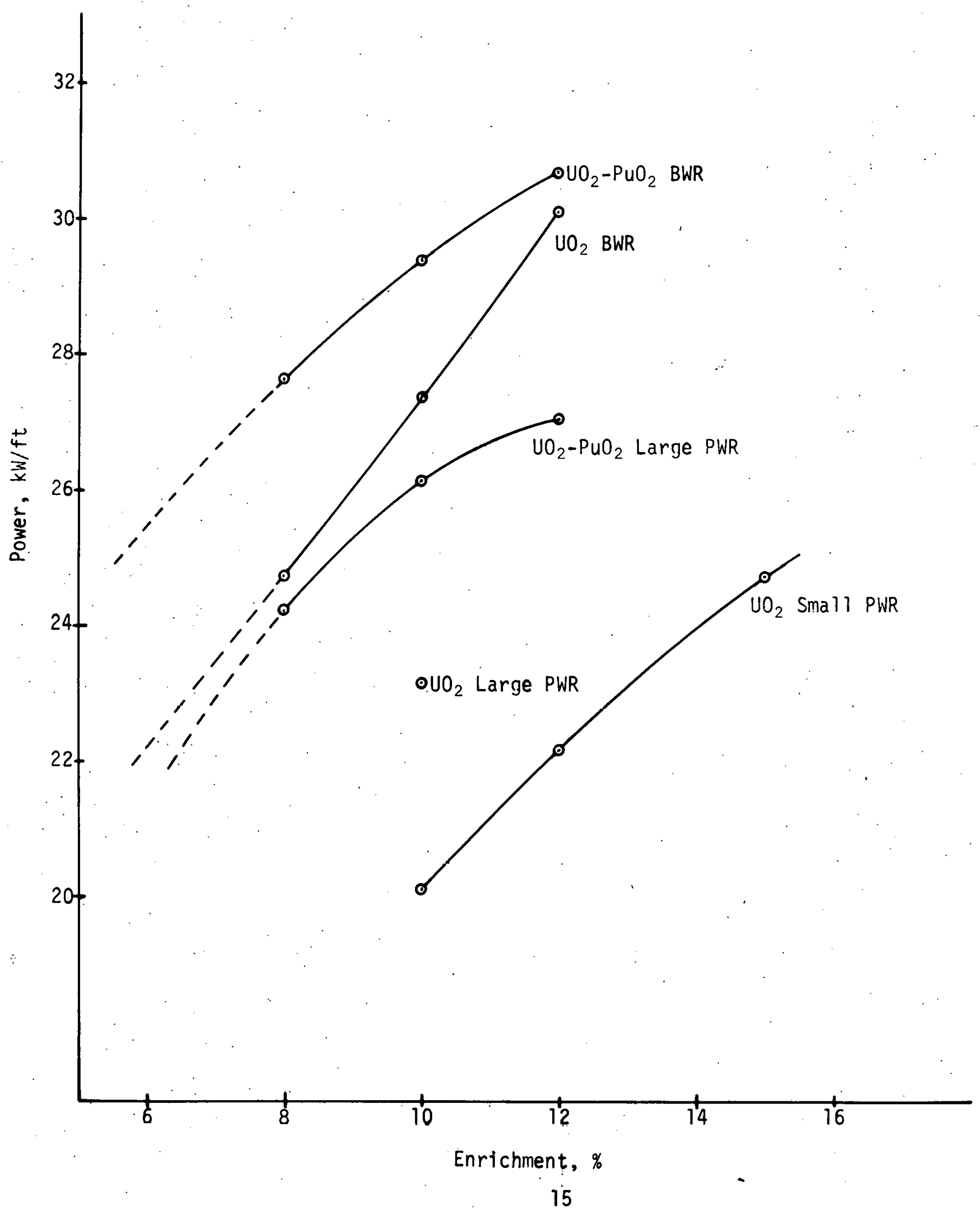


PWR pins must be enriched to $12 \% 235 \mathrm{U}$; the small $\mathrm{UO}_{2}$ PWR pins must be enriched to $16 \% 235 \mathrm{U}$; the mixed oxide BWR pins must be enriched to $6 \% \mathrm{Pu}$; and the mixed oxide large PWR pins must be enriched to $9 \% \mathrm{Pu}$.

The monte carlo calculated power distributions within the rods are shown in Figures 6 to 10 . It is seen that the power varies slightly azimuthally being higher towards the center of the bundle (lower left) and lower towards the outside of the bundle. The largest variation is in the radial direction. In the mixed oxide BWR pins, it varies by as much as $80 \%$ from the center to edge regions.

More than $90 \%$ of the power results from fissions induced by thermal neutrons. Therefore, the total power shape will be nearly the same as the thermal power shape. The thermal power shape calculated with BRT-I is shown in Figure 11 for various $\mathrm{UO}_{2}$ enrichments in a BWR pin. In Figure 12 , the thermal power shape is shown for various Pu enrichments in a BWR pin. As the fuel becomes blacker (increasing enrichment, or plutonium instead of $235 \mathrm{U}$ enrichment) the surface-tocenter power ratio increases. The effect of pin size on the thermal power shape is shown in Figure 13.

The effect of fuel density in the test pins could not be evaluated with monte carlo calculations because the change in power with changing density would be comparable to the statistical uncertainties on the powers. However, the effect was determined for $\mathrm{UO}_{2}$ fueled large PWR test pins with transport/ diffusion theory calculations. When the fuel density was increased from 91 to $97 \%$ T.D., the power was increased by $2.4 \%$. Thus, the power increases on $1 y 1 / 3$ as much as the fissile content increases. This is consistent with the results shown on Figure 5 for $\mathrm{UO}_{2}$ fuel where an increase of $50 \%$ in enrichment increases the power by $\sim 20 \%$. 
FIGURE 6。 Power Distribution in a $10 \%$ Enriched $\mathrm{UO}_{2}$ BWR Rod $27.38 \pm .23 \mathrm{~kW} / \mathrm{ft}$

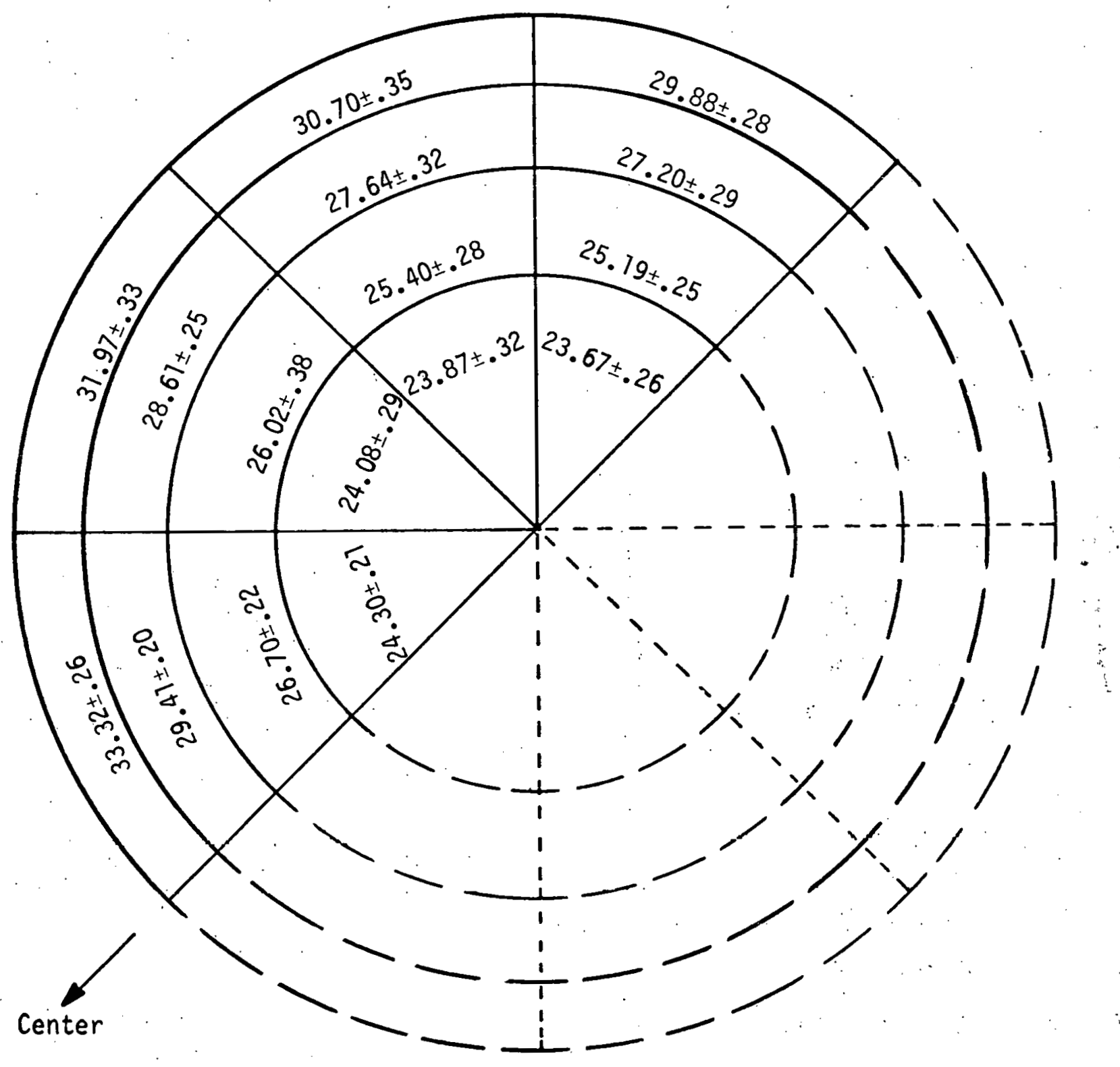


FIGURE 7. Power Distribution in a $10 \%$ Enriched $\mathrm{UO}_{2}$ Large PWR Rod $23.18 \pm .19 \mathrm{~kW} / \mathrm{ft}$

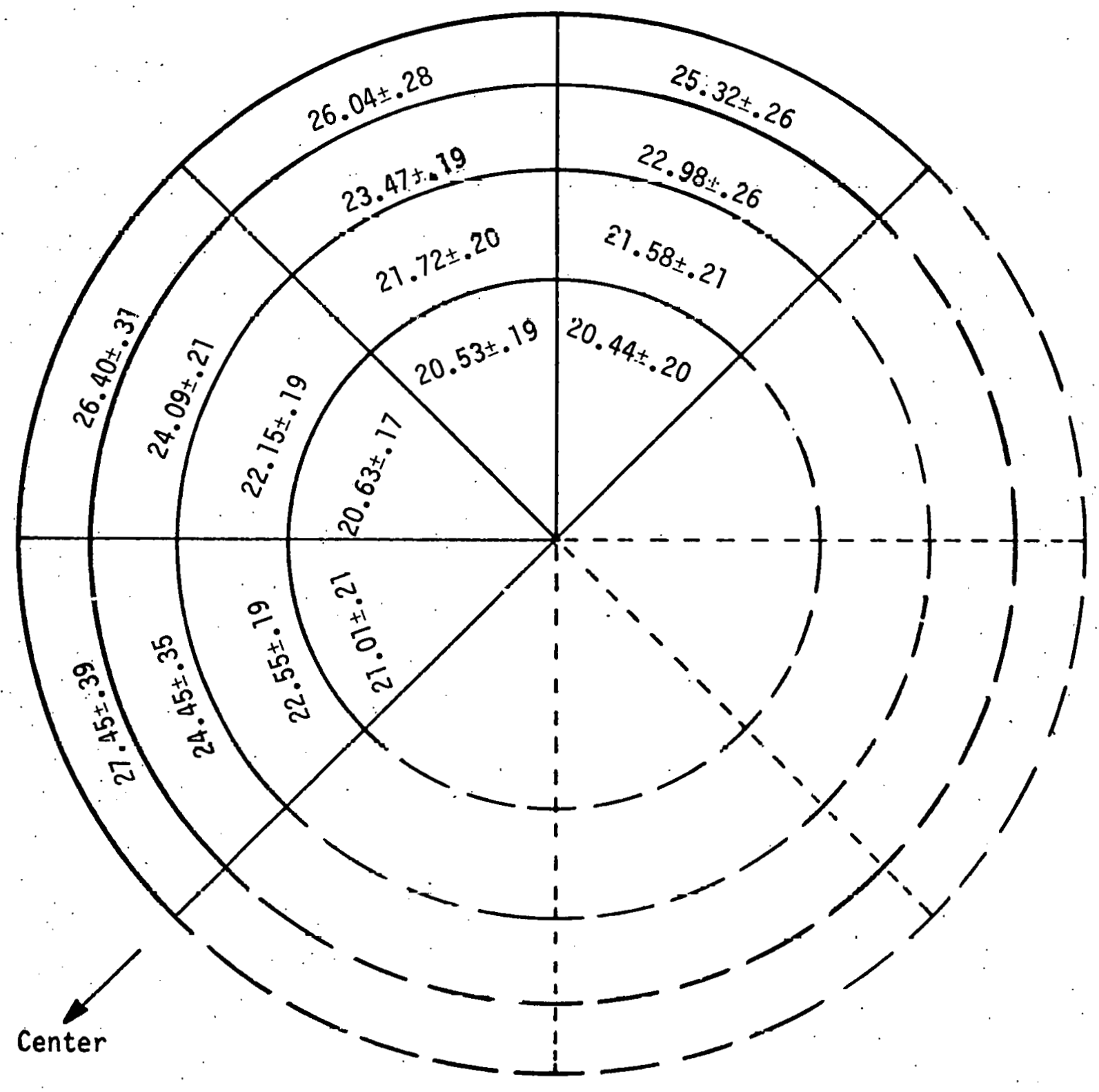


FIGURE 8. Power Distribution in a $10 \%$ Enriched $\mathrm{UO}_{2}$ Small PWR Rod $20.12 \pm .17 \mathrm{~kW} / \mathrm{ft}$

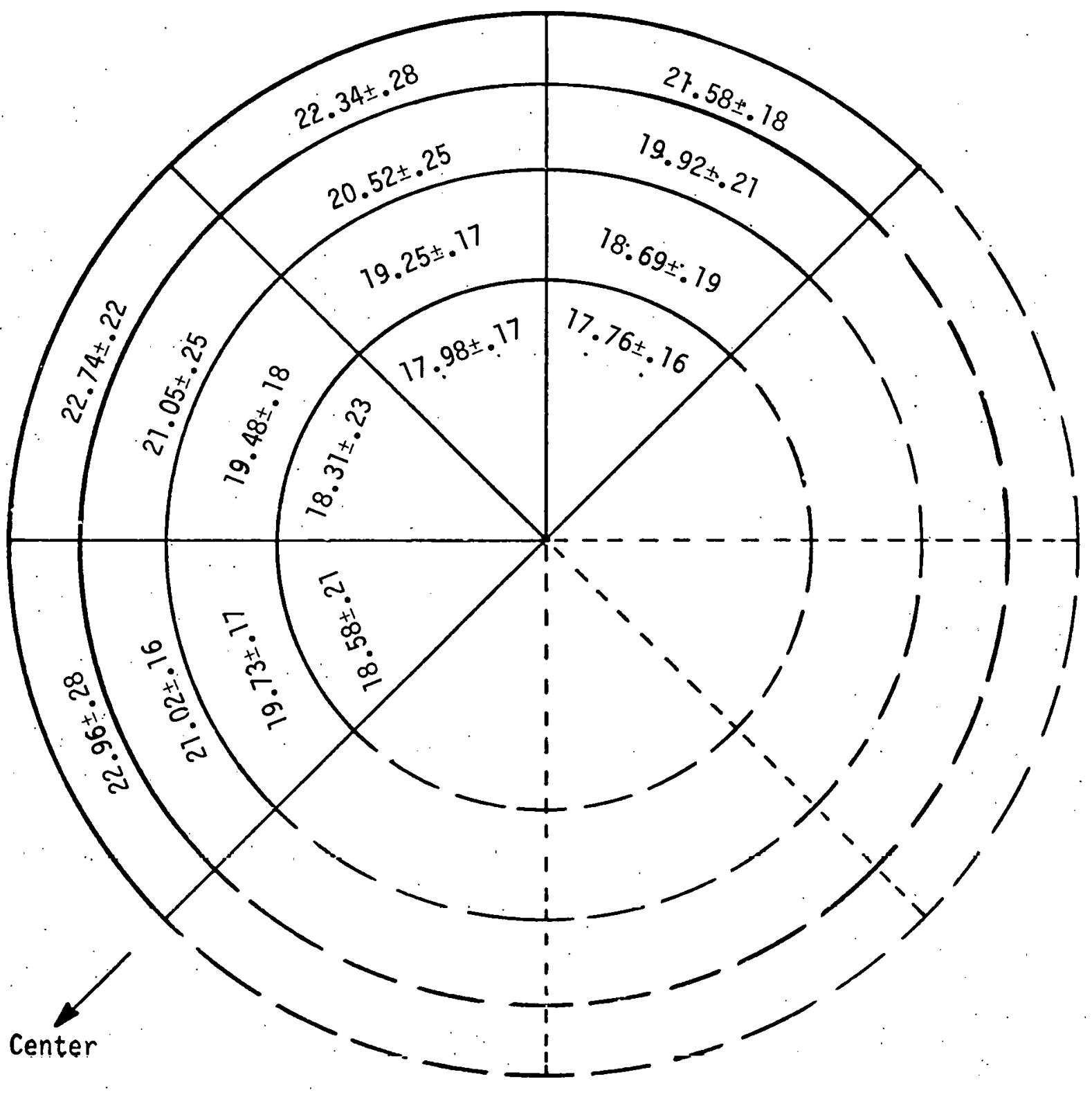


FIGURE 9. Power Distribution in an $8 \%$ Enriched $\mathrm{UO}_{2}-\mathrm{PuO}_{2}$ BWR Rod $27.65 \pm .24 \mathrm{~kW} / \mathrm{ft}$

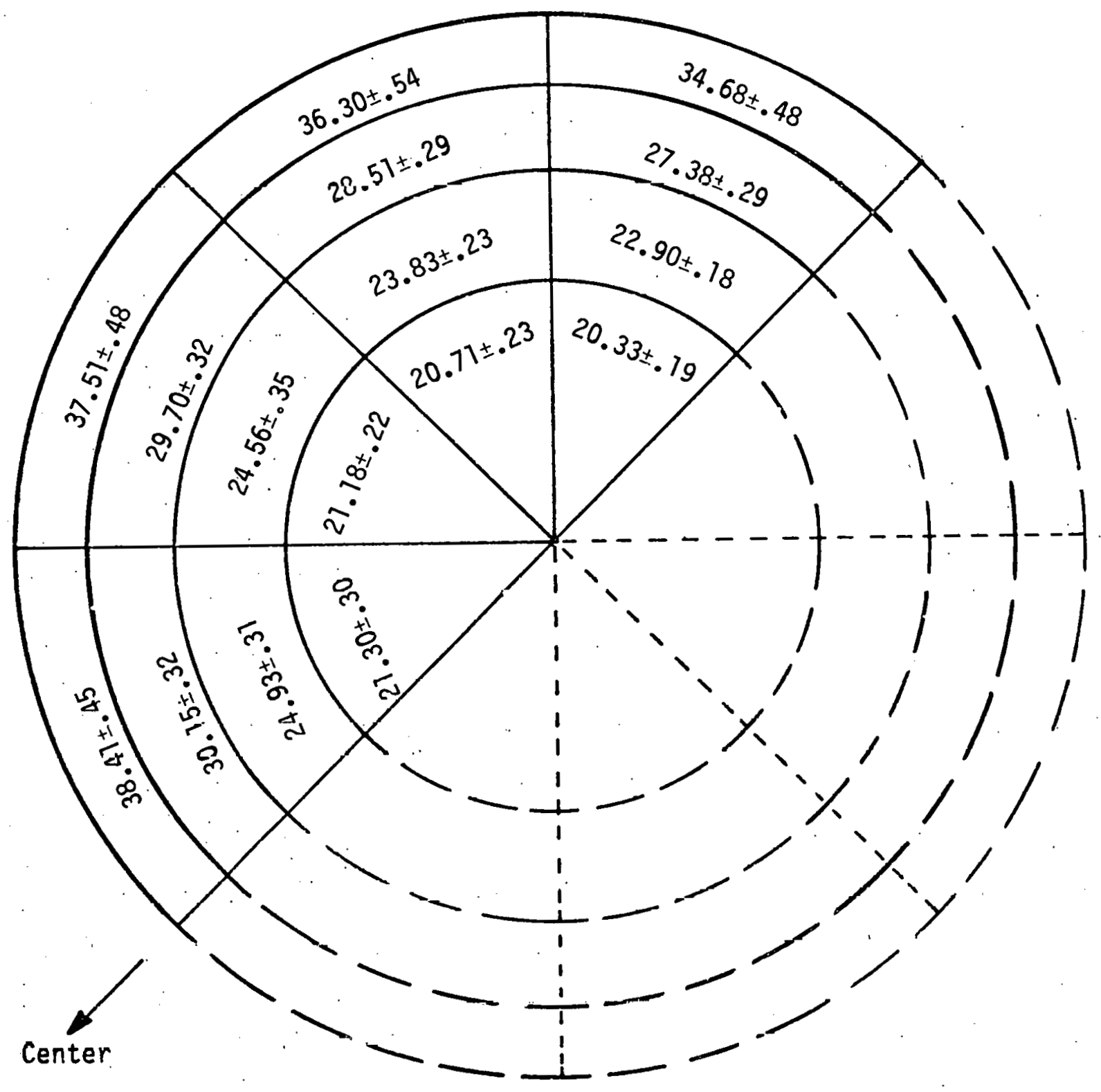


FIGURE 10. Power Distribution in an $8 \%$ Enriched $\mathrm{UO}_{2}-\mathrm{PuO}_{2}$ Large PWR Rod $24.22 \pm .28 \mathrm{~kW} / \mathrm{ft}$

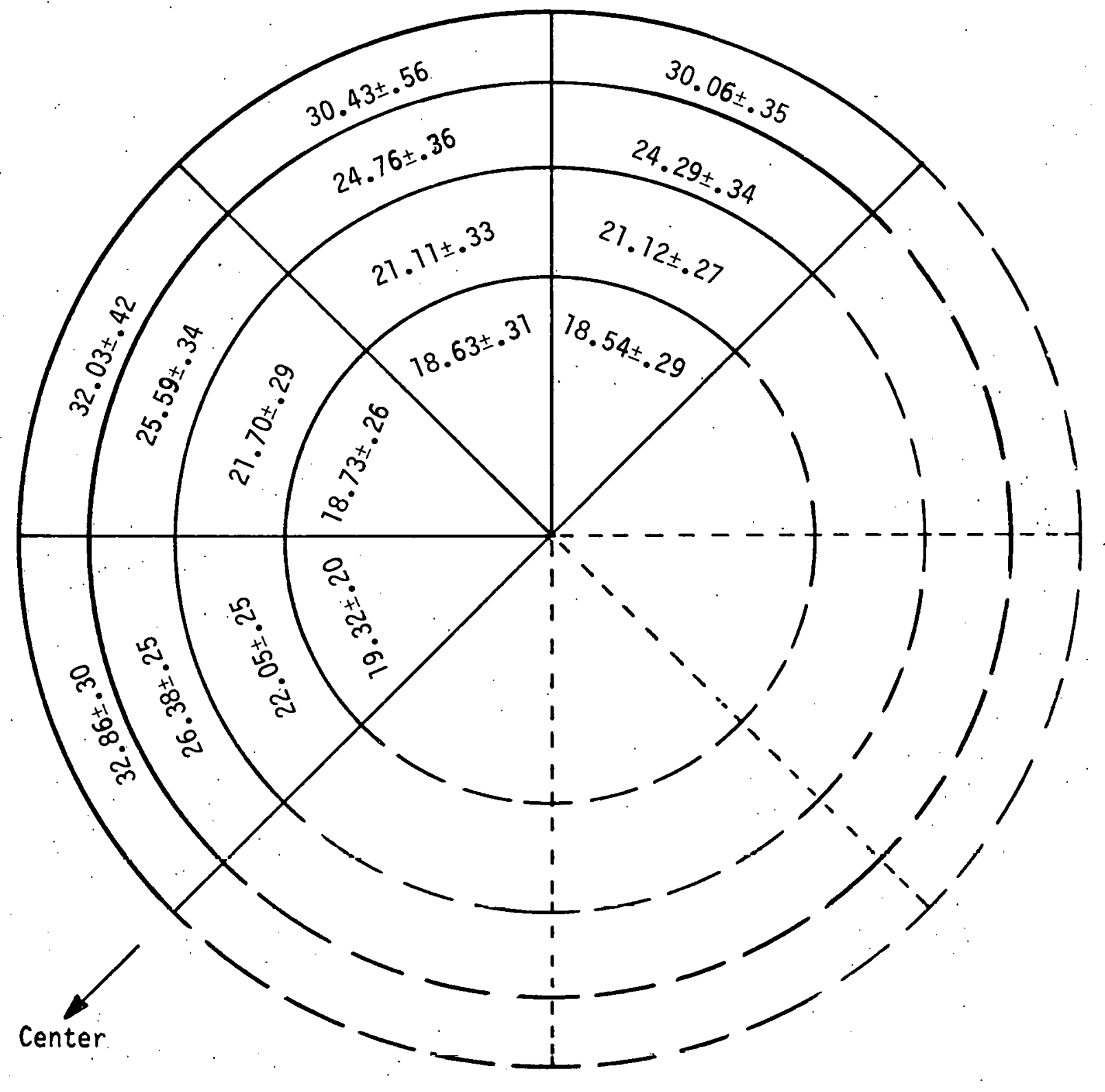


FIGURE 1.1. Effect of U-235 Enrichment on Therinal Power

Distribution for BWR Test Pins in PBF

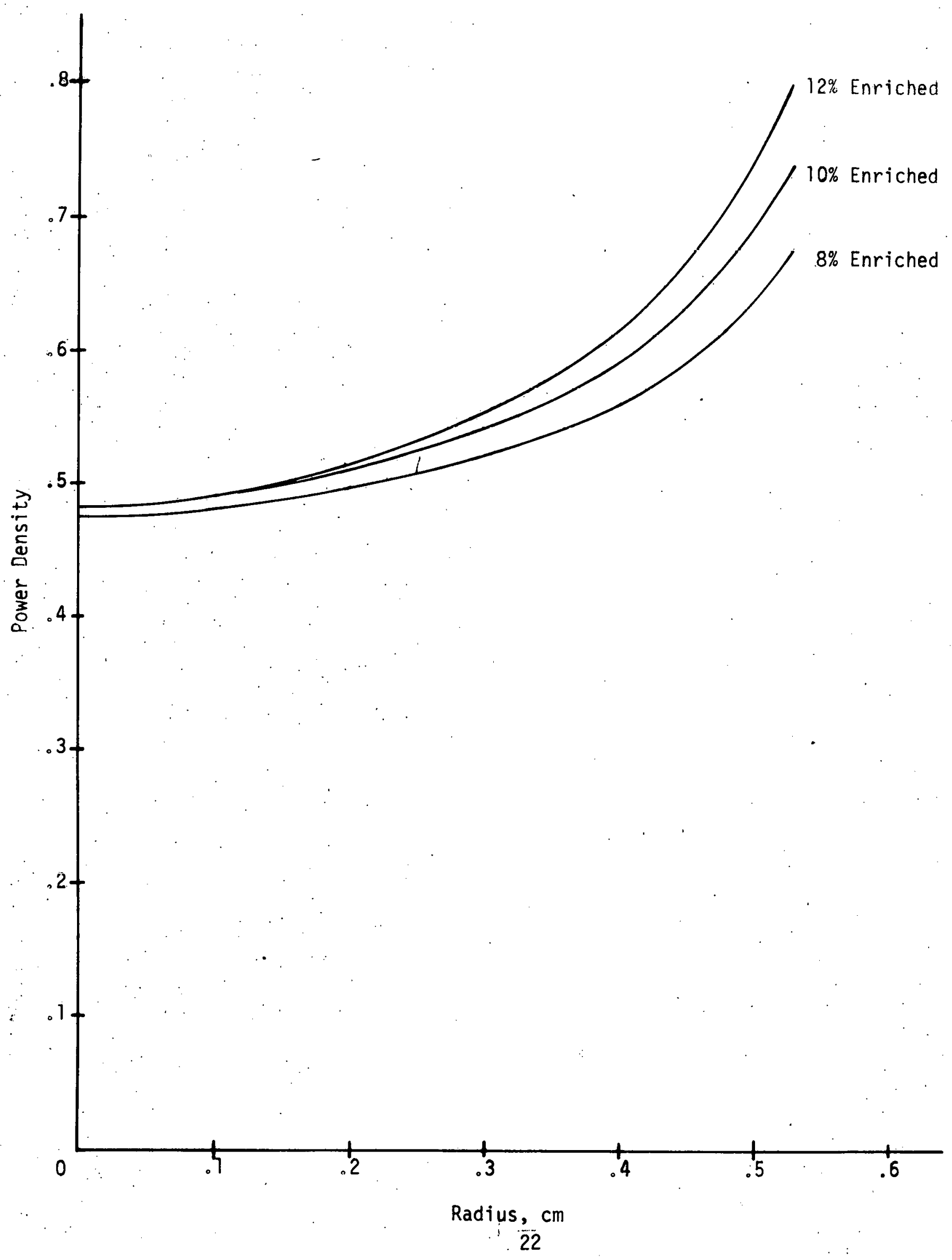


FIEURE 12. Effect of Pictonium Enrichient on Ther-al Power Distribution for BUR Test ins in P?

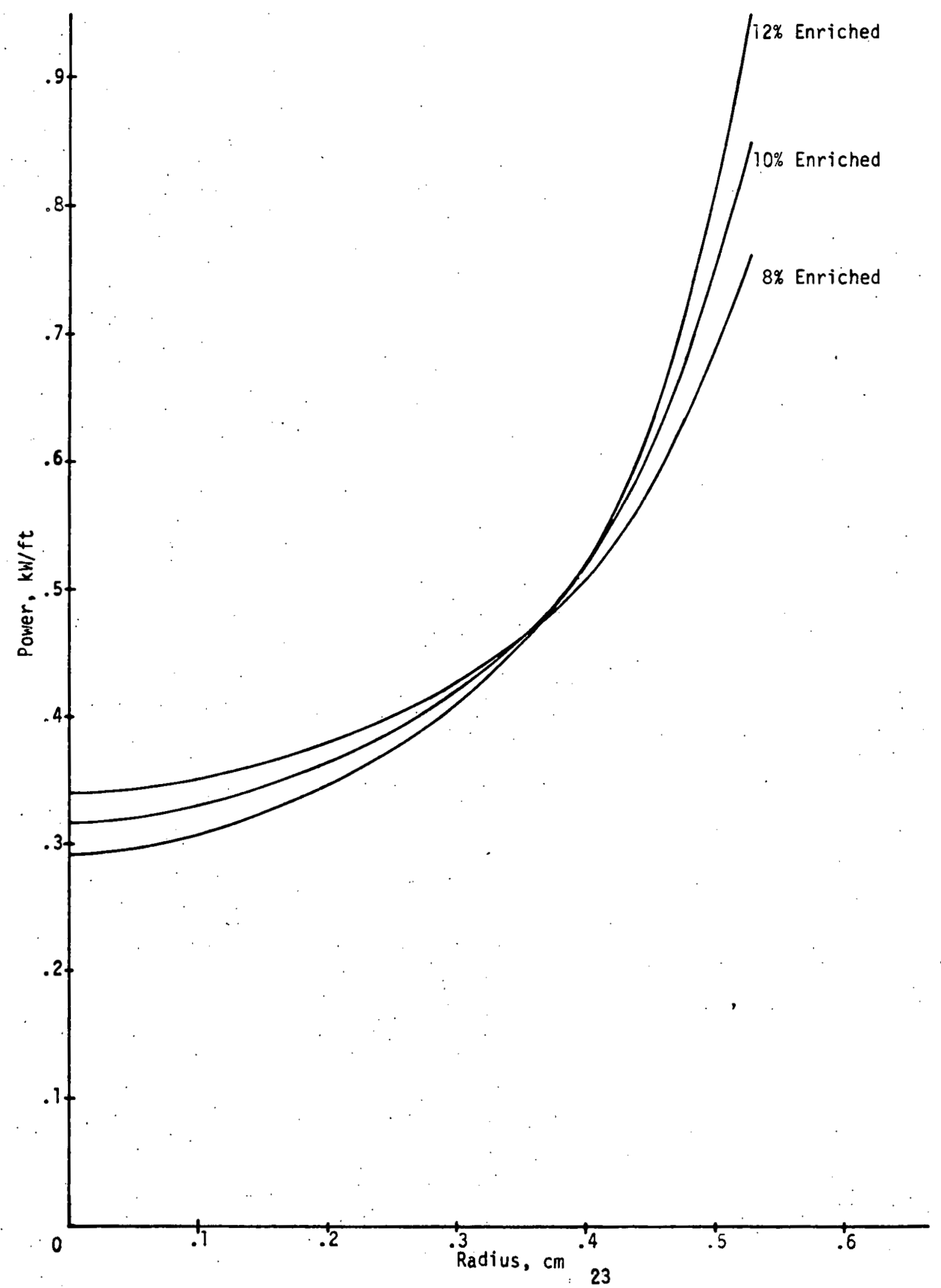


FIGURE 13. Effect of Pellet Size on Thermal Power Distribution for $10 \%$ Enriched $\mathrm{UO}_{2}$ Test Pins in PBF

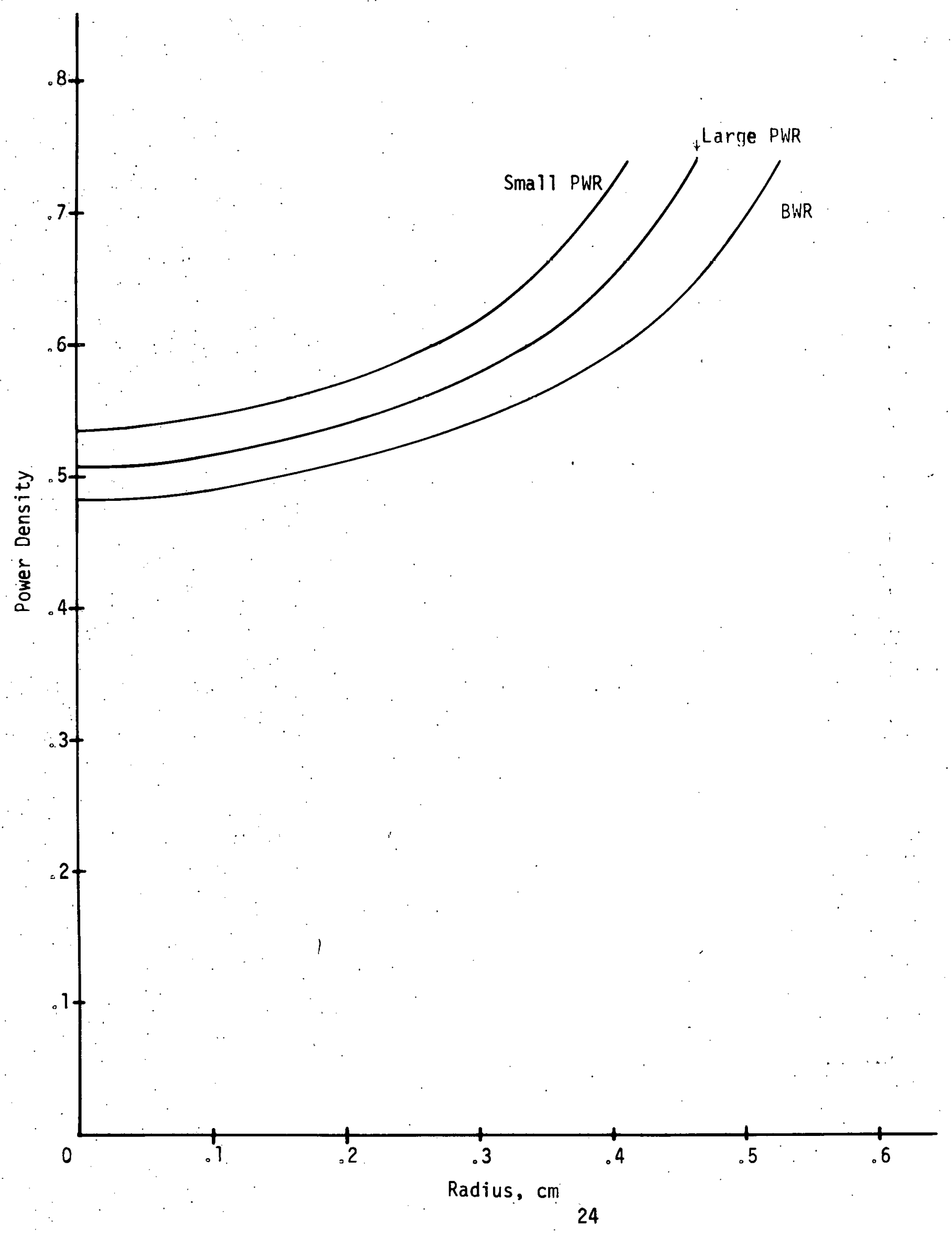


16-Rod Bundle

Monte carlo calculations were made to set the enrichments for a 16-rod bundle of large $\mathrm{UO}_{2}$ PWR pins as shown in Figure 2. The constraints were to produce as high as possible bundle averaged power while keeping the power in each rod as near to the average as possible. Four different enrichment distributions were tried. They are shown in Figure 14. The results of the four cases are summarized in Table VI. The first three cases were run only long enough to estimate the power distribution and total power. The 25/40/55 bundle has too low a power in the center rods. The $20 / 38 / 93$ bundle has a very flat power distribution but the power is too low. The 40/40/93 bundle has a very poor power distribution. The $30 / 55 / 93$ bundle has a poorer power distribution than the $20 / 38 / 93$ bundle but it generates $15 \%$ more power. It was the bundle chosen to converge with the monte carlo calculation. The power distributions in each rod are shown in Figures 15 to 17 . While the azimuthal variation was not very great in the 4-rod bundles, it is very great in the 16-rod bundle. In the $55 \%$ enriched edge rod (Figure 16) it is seen to vary by a factor of 2.5 from the inside outer edge to the outside outer edge. The fuel is black to thermal neutrons; hence, the neutron flux in the interior of the bundle is depressed relative to the neutron flux at. the exterior of the bundle.

\section{Accuracy}

The statistical uncertainty given for the monte carlo results reflects only a portion of the uncertainty in the answers. Things which contribute to the uncertainty besides the statistical uncertainty lie in two main areas. First is the cross-section and scattering-model uncertainties. Second is the uncertainty due to the monte carlo current source. The potential errors in the source are: 1) errors in magnitude due to the approximations and uncertainties 
FIGURE 14. Enrichment Distributions for Large PINR 16-Rod Bundle Calculations
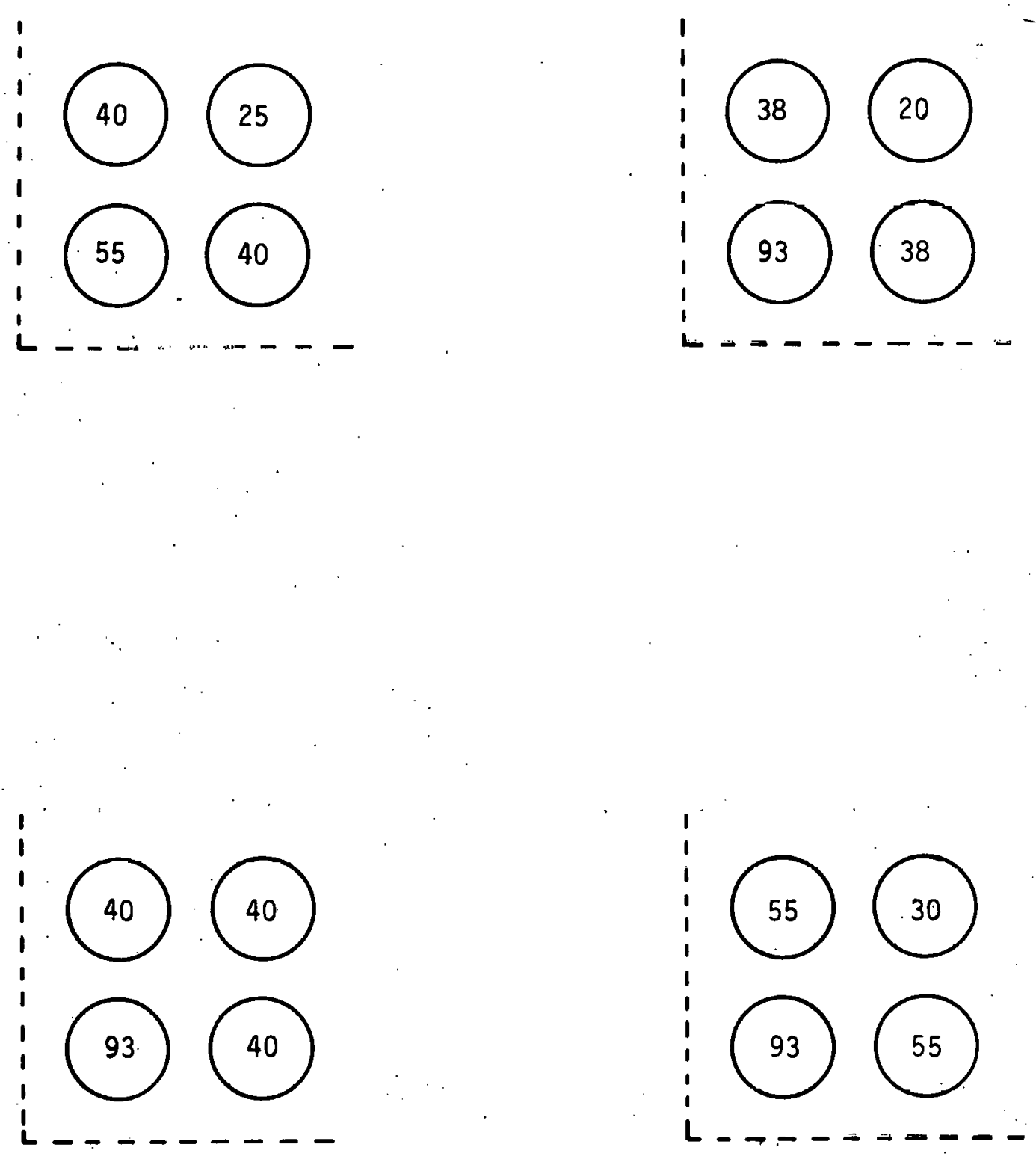
TABLE VI. 16-Rod Bundle Power Calculations at Various Enrichments

Bundle

Enrichment

Distribution

$25 / 40 / 55$

$20 / 38 / 93$

$40 / 40 / 93$

$30 / 55 / 93$
Peak Linear Power, kW/ft

\begin{tabular}{lccc}
\hline $\begin{array}{c}\text { Corner } \\
\text { Rod }\end{array}$ & $\begin{array}{c}\text { Edge } \\
\text { Rod }\end{array}$ & $\begin{array}{c}\text { Center } \\
\text { Rod }\end{array}$ & $\begin{array}{l}\text { Bundle } \\
\text { Average }\end{array}$ \\
& 15.1 & 10.9 & $14.19 \pm 0.65$ \\
14.7 & 14.6 & 13.6 & $14.39 \pm 0.42$ \\
20.4 & 15.1 & 13.8 & $16.14 \pm 0.59$ \\
$.86 \pm 0.10$ & $17.33 \pm 0.18$ & $13.67 \pm 0.13$ & $16.56 \pm 0.15$
\end{tabular}


FIGURE 15. Power Distribution in the Corner Rod of a 16-Rod Bundle ( $30 \%$ Enriched $\mathrm{UO}_{2}$ Large PWR Rod)

$17.86 \pm 0.10 \mathrm{~kW} / \mathrm{ft}$

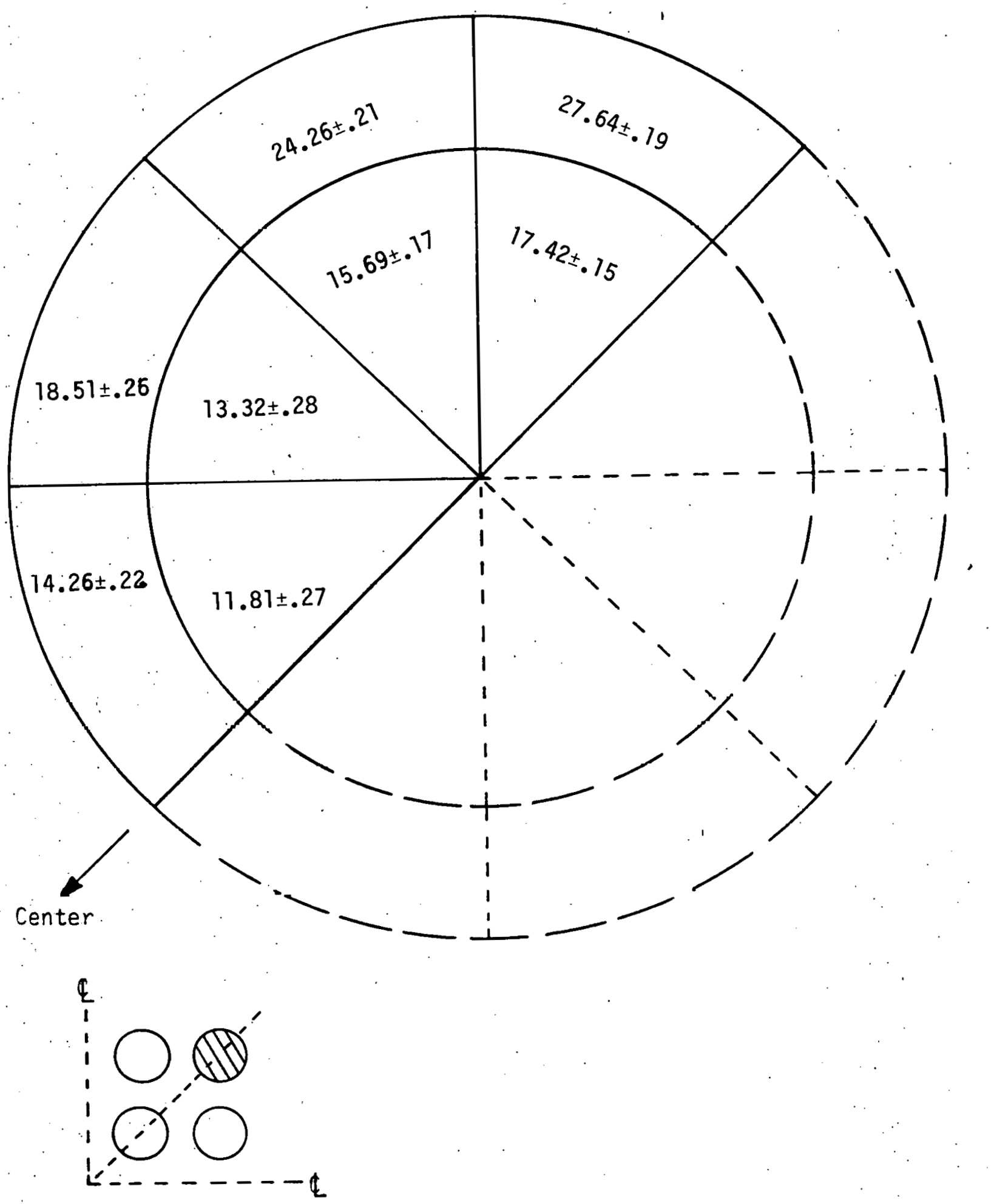


FIGURE 16. Power Distribution in the Ėdge Rod of a 16-Rod Bundle (55\% Enriched $\mathrm{UO}_{2}$ Large PWR Rod)

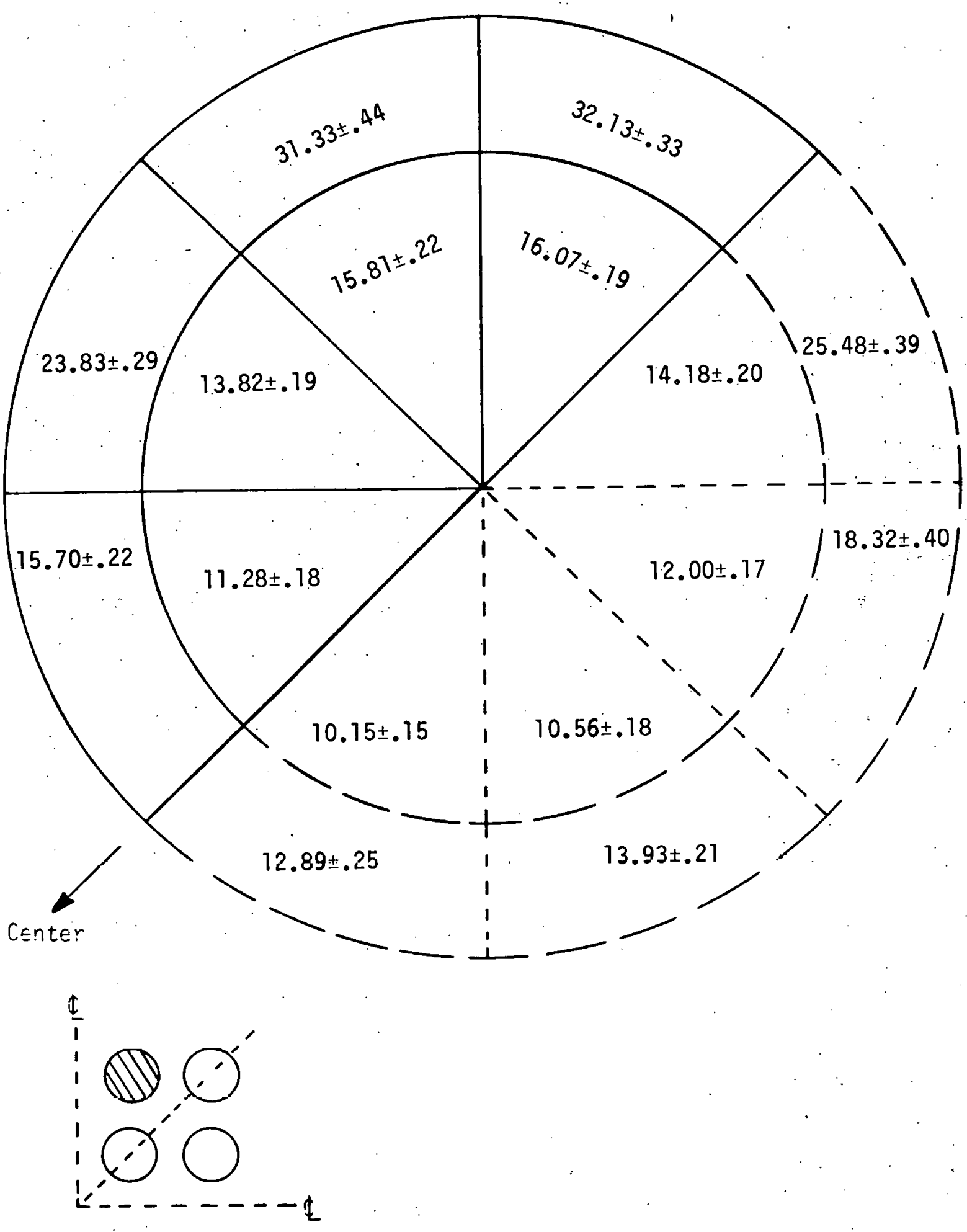


FIGURE 17. Power Distribution in the Center Rod of a 16-Rod Bundle (93\% Enriched $\mathrm{UO}_{2}$ Large PWR Rod)

$13.67 \pm 0.13 \mathrm{~kW} / \mathrm{ft}$

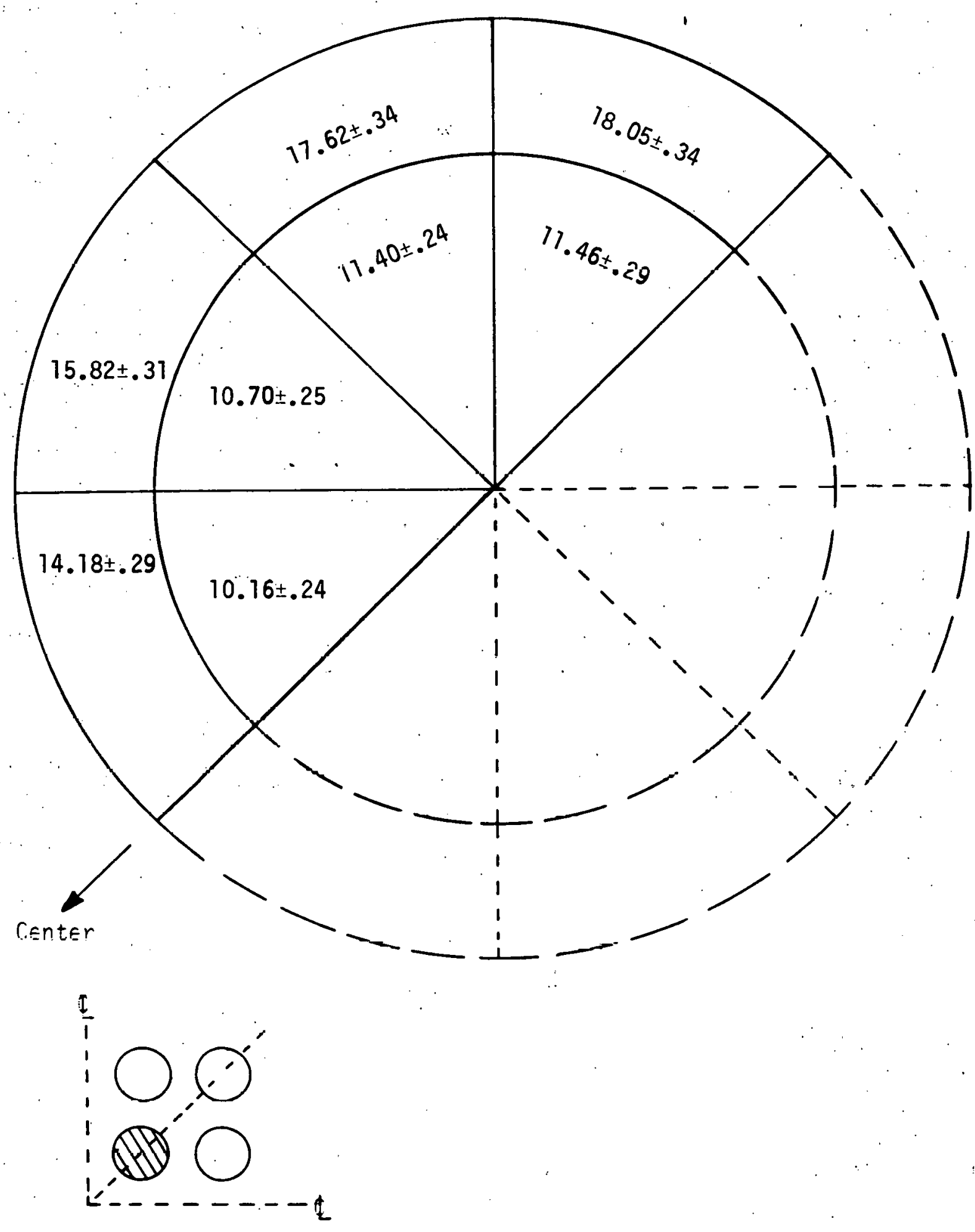


in the DTF-IV calculation, 2) errors in the angular distribution, and 3) errors in the energy distribution, especially in the thermal group. It was observed that the current's magnitude and angular detail are probably the most important parameters and could lead to the largest calculational errors. The monte carlo results are only as good as the transport theory calculation of current into the test region.

The way in which the Monte Carlo calculation was weighted seems to have made the calculation of powers relative to each other more accurate than the magnitude of the power. It is also felt that the relative powers are less dependent on cross section, method, or source errors than the magnitude of the power. 


\section{REFERENCES}

1. Letter A. J. Scott and F. J. Wheeler to W. J. Quapp, "Power Density in a 4-Rod Widely Spaced Cluster of Depleted MAPI Rods in PBF", Aerojet Nuclear Co., Dec. $37,1973$.

2. K. D. Lathrop, "DTF-IV, A FORTRAN-IV Program for Solving the Multigroup Transport Equation with Anisotropic Scattering", LA-3373, Los Alamos Scientific Laboratory, 1965.

3. D. H. Thomsen and T. M. Traver, "BMC-1: The Battelle Monte Carlo Code", BNWL-1433, Batte1le-Northwest, June 1970.

4. W. W. Little, Jr. and R. W. Hardie, "2DB, A Two-Dimensional Fast-Reactor Burnup Code", Computer Code Abstract, Nucl. Sci..Eng., 32, 275-276, 1968.

5. B. L. Rushton and W. R. Carpenter, "Methods Used for Physics Analysis of the Power Burst Facility and Computed Results for the Design Core", UC-80, Aerojet Nuclear Co., July 1971.

6. J. L. Carter, Jr., "HRG3: A Code for Calculating the Slowing-Down Spectrum in the $P_{1}$ and $B_{1}$ Approximation", BNWL-1432, Battelle-Northwest, June 1970.

7. C. L. Bennett and W. L. Purcel1, "BRT-I: Battelle Revised THERMOS", BNWL-1434, Battelle-Northwest, June 1970.

8. W. E. Vesely, F. J. Wheeler, and R. S. Marsden, "The RAFFLE General Purpose Monte Carlo Code", UC-32, Aerojet Nuclear Co., April 1973.

9. B. L. Rushton, Private Communication, May 22, 1974. 


\section{DISTRIBUTION}

No. of

Copies

OFFSITE

1 AEC Chicago Patent Group U. S. Atomic Energy Commission 9800 S. Cass Avenue Argonne, Illinois 60439

A. A. Churm

2. AEC Technical Information Center Oak Ridge, Tennessee 37830

22 Aerojet Nuclear Co. 550 - 2nd Street Idaho Falls, Idaho 83401

E. E. Burdick

G. W. Gibson

L. F. Johnson

P. M. Long

P. E. MacDonald

R. K. McCardel1 (10)

R. W. Miller

J. G. Procker

W. J. Quapp

J. H. Ramsthaler

B. L. Rushton

A. J. Scott

L. V. Thompson
No. of

Copies

ONSITE

12 Battelle Northwest

N. E. Carter

S. Goldsmith/C. R. Hann

C. M. Heeb

U. P. Jenquin (5)

R. C. Liikala

A. M. Sutey

D. H. Thomsen

R. D. Widrig

1 AEC Richland Operations Office

B. J. Melton 